\title{
Review Article on Current Applications and Future Concepts of Capsule Endoscopy
}

\author{
Helmut Neumann ${ }^{a}$ Lucía C. Fry ${ }^{b}$ Markus F. Neurath ${ }^{a}$ \\ ${ }^{a}$ Department of Medicine I, University of Erlangen-Nuremberg, Erlangen, and ${ }^{b}$ Department of Internal Medicine, \\ Gastroenterology and Infectious Diseases, Marienhospital Bottrop, Bottrop, Germany
}

\section{Key Words}

Capsule endoscopy · Small bowel • Advanced imaging •

Endomicroscopy $\cdot$ Inflammatory bowel disease

\begin{abstract}
Since the advent of capsule endoscopy (CE) more than one decade has passed. During this time, extensive efforts have been made to proof the relevance of CE for diagnosis of various disease entities within the esophagus, small bowel, and colon. To date, the most common indications for CE are obscure gastrointestinal bleeding, Crohn's disease, polyposis syndromes and evaluation of patients with complicated celiac disease. In this review we will focus on the current clinical applications of CE for imaging of the esophagus, small bowel and colon and will additionally give an outlook on future concepts and developments of CE.
\end{abstract}

Copyright $\odot 2013$ S. Karger AG, Basel

\section{Introduction}

Since the introduction of capsule endoscopy (CE) in 2000 , various studies have shown the potential of this minimally invasive technique to improve diagnostic outcomes among a variety of gastrointestinal (GI) conditions [1-58].

\section{KARGER}

Fax +4161306 1234

E-Mail karger@karger.ch

www.karger.com
(C) 2013 S. Karger AG, Basel

0012-2823/13/0872-0091\$38.00/0

Accessible online at:

www.karger.com/dig
To date, multiple CE systems from different companies are available. Nevertheless, currently only the Given M2A video capsule system (Given Imaging Ltd., Yoqneam, Israel) and the Olympus Endocapsule (Olympus, Tokyo, Japan) are FDA and CE approved. Capsule systems are available for examination of the esophagus, small bowel and colon. While suspected small bowel stenosis is a contraindication for performing $\mathrm{CE}$ a patency capsule (Agile capsule, Given Imaging) was developed for these patients. This capsule is a self-dissolving capsule with the same size as the conventional CE and contains a radiofrequency identification tag that allows it to be detected by a scanning device placed on the abdominal wall. In addition, it has a radiopaque coating that permits its location within the bowel using fluoroscopy. When its passage is blocked by a stenosis or tumor, the patency capsule dissolves within $40-80 \mathrm{~h}$ after ingestion.

Although the capsule is easily ingested and swallowed by most individuals, patients with severe dysphagia, large Zenker's diverticulum, pill phobia, significant gastropareses, and small children may have problems ingesting the device. For these situations, a capsule-loading device (AdvanCE, US Endoscopy, Mentor, Ohio, USA) is available to directly deliver the capsule into the stomach or duodenum. The disposable device is a $2.5-\mathrm{mm}$ singlesheathed device which is first preloaded through the working channel of a standard endoscope. The activated

Prof. Helmut Neumann, MD

Department of Medicine I, University of Erlangen-Nuremberg Ulmenweg 18

DE-91054 Erlangen (Germany)

E-Mail helmut.neumann@uk-erlangen.de 
CE is than loaded into the specialized capsule cup and afterwards the endoscope and the loading device are carefully advanced through the esophagus. After reaching the stomach or duodenum the $\mathrm{CE}$ is released and the endoscope is withdrawn.

Based on a recent systematic review, the following were identified as the most common indications for CE: obscure GI bleeding, accounting for $66 \%$ of interventions, clinical symptoms only (10.6\%), Crohn's disease (10.4\%), others (7\%), neoplastic lesions (3.5\%), celiac disease (1.7\%), and healthy subjects (0.8\%) [2]. It is important to emphasize that $\mathrm{CE}$ has a low diagnostic yield in the evaluation of patients with abdominal pain or diarrhea in the absence of anemia or elevation of inflammatory markers [3].

\section{Technical Specifications}

At the time of writing this review, two FDA and CEcertified capsule devices are available consisting both of disposable plastic capsules. The Given small bowel capsule measures $11 \times 26 \mathrm{~mm}$ and weights less than $4 \mathrm{~g}$. The field of view is 140 degrees and the system can detect objects less than $0.1 \mathrm{~mm}$. The SB2/4 capsule is capable of capturing four images per second. The operating time is between 6 and $8 \mathrm{~h}$. The Given capsule for esophageal diseases (PillCam Eso) has the same size like the SB capsule but is capable to take up to 18 images per second as it passes down the esophagus. The Endocapsule system from Olympus has a maximum field of view of $145^{\circ}$, a depth of field between 0 and $20 \mathrm{~mm}$ and a sampling rate of 2 frames per second. The dimensions of the capsule are $11 \mathrm{~mm}$ in diameter and $26 \mathrm{~mm}$ in length. The operating time of the device is about $8 \mathrm{~h}$.

\section{Relative and Absolute Contraindications}

It is recommended to use the $\mathrm{CE}$ with caution in patients with known or suspected GI obstruction, fistulas, or motility disorders [4]. Nonexcretion of the CE was reported to occur in less than $1 \%$ of patients [5]. In this context, retention only occurred in cases with localized pathology while no retention has been reported in normal subjects or those with small bowel diverticulosis or appendiceal orifices [6]. In patients with suspected Crohn's disease and obscure GI bleeding capsule retention has been reported in between 1.5 and 5\%. Although CE retention is usually clinically asymptomatic, it may require ei-

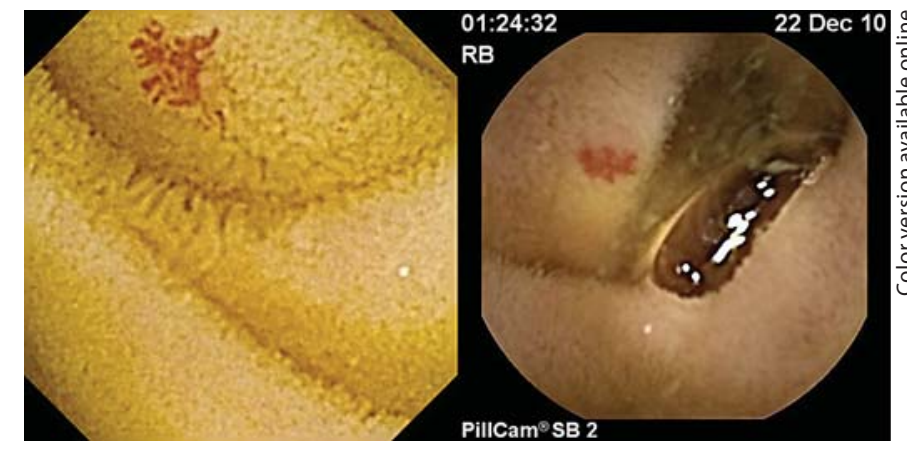

Fig. 1. Typical appearance of angiovascular malformations visualized using $\mathrm{CE}$.

ther endoscopic or surgical removal to avoid further complications [7]. While there has been concern about the use of defibrillators and cardiac pacemakers, recent evidence suggests that $\mathrm{CE}$ can be safely performed in these patients with appropriate monitoring. Moreover, it was shown that capsule-induced electromagnetic interference remains a possibility but is unlikely to be clinically important. Cardiac pacemaker-induced interference of CE is also possible, but is infrequent and does not result in loss of images transmitted by the capsule [8]. In contrast, patients should not undergo magnetic resonance imaging after having excreted the $\mathrm{CE}$. Plain radiographs can easily identify the CE in case of suspicion of any retention.

\section{Patient Preparation}

Patient preparation for $\mathrm{CE}$ of the esophagus is performed after the patient has fasted for at least $2 \mathrm{~h}$. For small bowel CE there are several accepted preparation methods, which include fasting since the day before, clear liquid diet, the ingestion of 2-4 liters of polyethylene glycol solution or the use of mannitol. In addition, some experts recommend the use of simethicone before the ingestion of the capsule to reduce intraluminal foam and bubbles. Bowel cleansing for colon CE is of paramount importance and it is still under development and improvement.

Because $\mathrm{CE}$ is a minimally invasive technology patient compliance is good in most cases. Only a minority of patients have problems to swallow the capsule and some patients experienced problems drinking the amount of fluid necessary for optimal colon CE examination. 


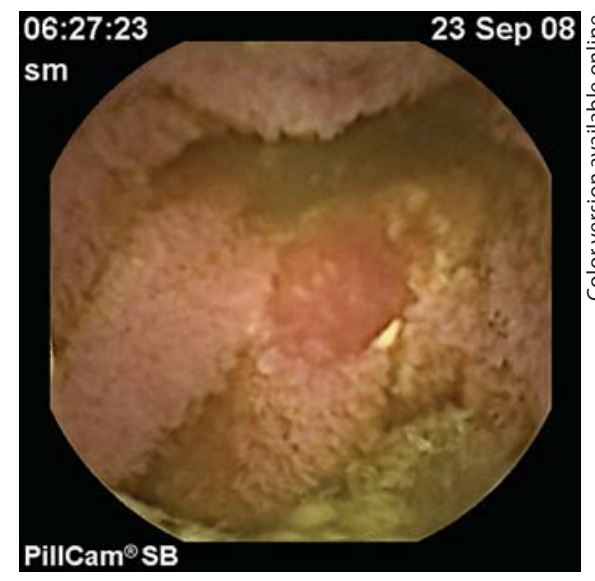

Fig. 2. Superficial ulcerous lesion in Crohn's disease.

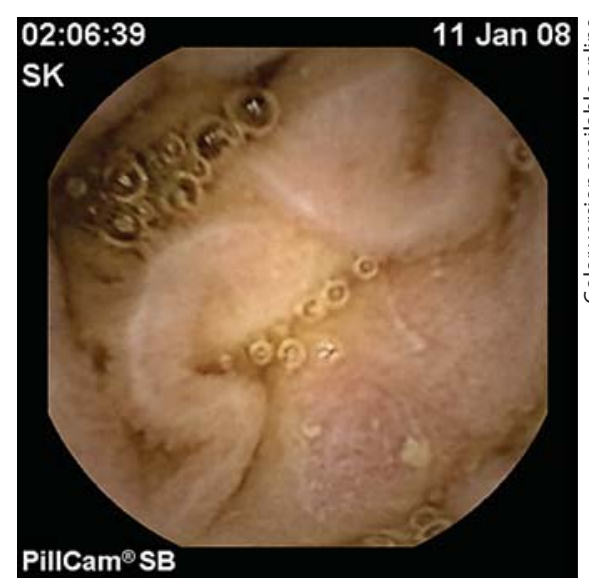

Fig. 5. CE visualizes NSAID-induced small-bowel lesion.



Fig. 3. Engorged and flattened intestinal villi in patient with celiac disease.

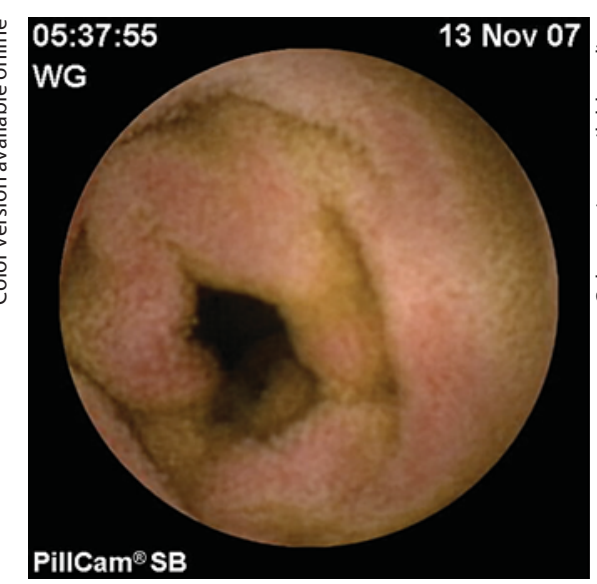

Fig. 6. Appearance of enteropathy-associated $\mathrm{T}$ cell lymphoma on $\mathrm{CE}$.

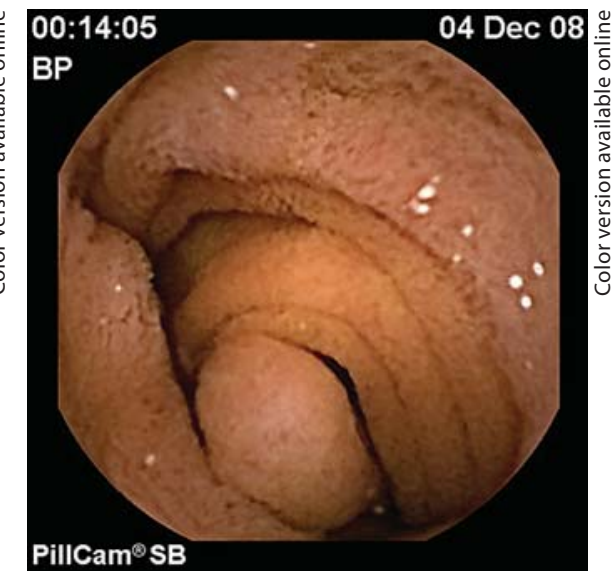

Fig. 4. Small bowel polyp in a patient with Peutz-Jeghers syndrome visualized using CE.

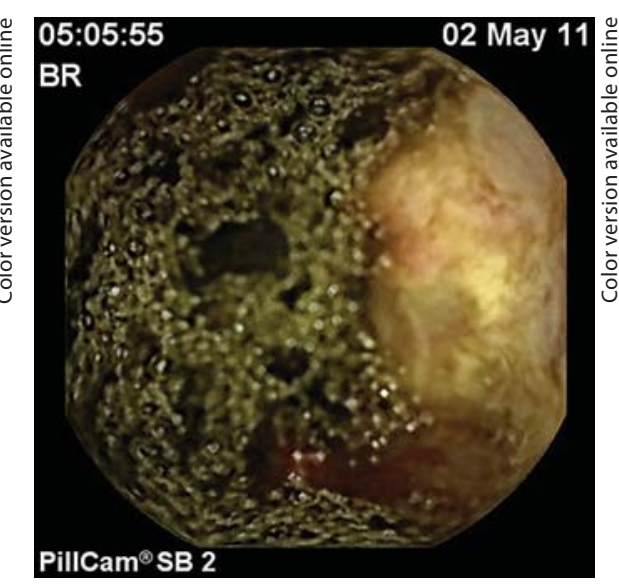

Fig. 7. Small-bowel carcinoid diagnosed with CE.

\section{Clinical Applications}

\section{Esophagus}

GERD and Barrett's Esophagus

Eliakim et al. [9] presented the results of a multicenter trial evaluating the diagnostic accuracy of PillCam ESO versus upper endoscopy in patients with chronic gastroesophageal reflux disease. Overall, 106 patients were included and of those 66 patients had positive esophageal findings. CE identified esophageal abnormalities with a sensitivity and specificity of 92 and $95 \%$, respectively. The per-protocol sensitivity, specificity, positive predictive value, and negative predictive value of $\mathrm{CE}$ for Barrett's esophagus were 97, 99, 97 and 99\%, respectively, and for esophagitis 89, 99, 97 and 94\%, respectively. In this study, CE was preferred over standard upper endoscopy by all patients.

In 2008, Gralnek et al. [10] presented the results of the second-generation CE (PillCam ESO 2) for the detection of esophageal diseases. Compared with upper endoscopy for detecting suspected Barrett's esophagus and esophagitis, the PillCam ESO 2 had a sensitivity of $100 \%$ and a specificity of $74 \%$, and a sensitivity of $80 \%$ and a specificity of $87 \%$, respectively.

A nother study compared the accuracy of upper endoscopy with esophageal CE in patients at risk of esophageal squamous cell cancer [11]. Overall, 68 patients were included. Sensitivity of CE for neoplasia diagnosis was $46 \%$. 
Fig. 8. Proposed algorithm for the diagnosis of obscure GI bleeding.



On a per-patient basis, the sensitivity, specificity and positive and negative predictive value of CE were 63, 86, 77 and $76 \%$, respectively. Therefore, CE seemed not to be sensitive enough to diagnose neoplasic lesions in the esophagus.

In conclusion, $\mathrm{CE}$ of the esophagus seemed to be a convenient and sensitive method for visualization of Barrett's esophagus and esophagitis but is not sensitive enough to diagnose SCC.

\section{Esophageal Varices}

Various studies have evaluated the potential of CE for diagnosis of esophageal varices. One recent meta-analysis included 9 studies with 631 patients [12]. The pooled sensitivity and specificity of CE for detecting esophageal varices were 83 and $85 \%$, respectively. Nevertheless, CE was not comparable to upper endoscopy. It was therefore concluded that esophageal CE could be an acceptable alternative to conventional endoscopy in certain situations but could not be recommended to replace standard upper endoscopy.

\section{Small Bowel}

Obscure Gastrointestinal Bleeding

Obscure GI bleeding is defined as either occult or overt bleeding of unknown origin that persists or recurs after an initial negative endoscopic evaluation including colonoscopy and EGD. Obscure GI bleeding accounts for most (about 66\%) of CE interventions and CE has been recommended as the 3 rd diagnostic test for patients with obscure GI bleeding (after at least one normal upper and lower endoscopy) [2, 13]. It was shown that about 20-38\% of patients with normal upper and lower endoscopy have significant intestinal lesions [14, 15] (fig. 1). Previous studies have demonstrated that $\mathrm{CE}$ is superior to radiographic studies, including barium follow-through and CT enterography $[16,17]$. Moreover, a pooled analysis of 7 prospective studies showed a CE yield of $71 \%$ for identification of a bleeding source compared to push enteroscopy [18]. In case of ongoing bleeding, CE detected the bleeding source in $92 \%$. In case of heme-positive stool and anemia, CE detected the bleeding source in $44 \%$ and in patients with a prior overt bleeding in about $13 \%$ of patients.

When comparing CE with intraoperative enteroscopy, the sensitivity, specificity positive, and negative predictive value of CE was 95, 75, 95 and $86 \%$, respectively [19]. These findings are in line with other published data [2022].

Balloon-assisted endoscopy (e.g. double-balloon or single-balloon endoscopy) has the potential to visualize the whole small intestine. One recent study compared double-balloon endoscopy with CE and identified nearly concordant findings in 12 out of 13 bleeding patients. In 1 patient, CE missed an ulcer [23]. Sheibani et al. [24] evaluated the long-term impact of $\mathrm{CE}$ in patients referred 
Table 1. Indications for $\mathrm{CE}$ according to different locations (most common indications are underlined)

Esophagus
Gastroesophageal reflux disease
Barrett
Esophageal varices
Small bowel
Obscure gastrointestinal bleeding
Intestinal tumors
Crohn's disease
Celiac disease
Colon
Polyps
Cancer
General
Diarrhea
Abdominal pain

for iron deficiency anemia. CE had a diagnostic yield of $61 \%$ and the CE-based diagnosis led to a therapeutic intervention in about $26 \%$ of patients. Another study included 100 consecutive cases with recent negative upper and lower endoscopy [20]. In patients with ongoing overt GI bleeding CE yielded in positive findings in about $92 \%$. In contrast, in patients with guaiac-positive stool tests, iron deficiency anemia and previous overt GI bleeding, CE yielded positive findings in about 44 and 13\%, respectively. Sensitivity, specificity and positive and negative predictive values of CE were $89,95,97$ and $83 \%$, respectively. Figure 8 highlights our proposed algorithm for the diagnosis of obscure GI bleeding.

Intestinal Tumors

The frequency of intestinal tumors among patients investigated using $\mathrm{CE}$ for obscure bleeding ranges from 6 to $12 \%$ [25]. The most common tumors in the small bowel include adenocarcinomas, lymphomas, GI stromal tumors, neuroendocrine tumors and metastasis [26]. Nevertheless, there are several cases of missed tumors of the small bowel using CE, probably because these lesions grow predominantly in the submucosa and extraluminally rather than into the small bowel lumen [27, 28]. Moreover, small bowel tumors are sometimes relatively small and can therefore easily be missed with CE. In patients with polyposis syndromes, CE was shown to detect more polyps in comparison to small bowel follow through [29]. Moreover, CE seemed to be more effective than positron emission tomography in the detection of malignant melanomas and metastases [30]. Detection rates between

Current Applications and Future

Concepts of Capsule Endoscopy
MRI and CE for identification of polyps larger than 15 $\mathrm{mm}$ were similar while $\mathrm{CE}$ was more sensitive to diagnose smaller intestinal polyps [31]. Nevertheless, one potential limitation of CE is the examination of the proximal duodenum and the periampullary region which could only be visualized in about $10 \%$ of examinations in one recent study [32]. In patients with familiar adenomatous polyposis, CE was superior to conventional white-light endoscopy for the detection of small bowel polyps, but not for duodenal neoplasia [33]. Also for other hereditary polyposis syndromes, including Peutz-Jeghers syndrome and Lynch syndrome, recent data indicate that $\mathrm{CE}$ is a safe and effective method for small bowel surveillance and even yield in a better reproducibility than with CT enteroclysis [34-36] (fig. 4). Nevertheless, despite these promising results surveillance of the small bowel is currently mostly not recommended in Lynch syndrome [37].

\section{Crohn's Disease}

Various studies have shown the potential of CE for diagnosis of Crohn's disease [38-42] (fig. 2). Eliakim et al. [38] compared CE to barium follow through and computed tomography (CT) in patients with suspected Crohn's disease. CE yielded a diagnosis in $77 \%$ of patients, compared to 23 and $20 \%$ for barium follow through and CT, respectively. These results were also confirmed by other investigators $[39,40]$. Notably, one recent small study including 39 patients reported on a sensitivity and specificity of 89 and $100 \%$, respectively [41]. These results need to be critically discussed, because Crohn's disease-associated mucosal changes are nonspecific for the disease and can also be observed in up to $14 \%$ of healthy volunteers and in patients taking nonsteroidal anti-inflammatory drugs [42] (fig. 5). Therefore, it is important for the endoscopist to read the CE findings with extensive knowledge about the patient's history. One recent published metaanalysis evaluated the diagnostic yield of CE in patients with suspected and established small bowel Crohn's disease in comparison to push enteroscopy, ileocolonoscopy, small bowel radiography, CT enterography and magnetic resonance tomography [43]. The meta-analysis revealed that CE was superior to small bowel radiography, CT enterography and ileocolonoscopy in the evaluation of patients with suspected Crohn's disease. In patients with established Crohn's disease, CE was superior to small bowel radiography, CT enterography and push enteroscopy. Similar results were shown in another recent meta-analysis from Leighton et al. [44]. In contrast to these data, Solem et al. [45] found that the sensitivity of CE for diagnosis of active small bowel Crohn's disease was not sig- 




Fig. 9. Proposed algorithm for the diagnosis of suspected small bowel Crohn's disease.

nificantly different from CT enterography, ileocolonoscopy, or small bowel follow through. The authors concluded that CE has only a limited value as the first-line test for small bowel Crohn's disease. Importantly, the risk of capsule retention in patients with known Crohn's disease must be considered and analyzed before the ingestion of CE. Although patients with suspected Crohn's disease have the same risk of retention as compared with the general population (1.6\%), in patients with known or established Crohn's disease this risk of retention is up to $13 \%$, with the consequent need of surgery in some cases [46]. Of note, balloon-assisted endoscopy is mostly successful to remove foreign bodies from the small bowel [47]. Figure 9 highlights our proposed algorithm for the diagnosis of Crohn's disease.

\section{Celiac Disease}

Advanced celiac disease is characterized by villous atrophy which can be visualized using CE Figure 3. One recent published meta-analysis described an overall pooled sensitivity of $89 \%$ (95\% CI 82-94) and specificity of $95 \%$ (95\% CI 89-98) for CE in celiac disease [48]. In a subgroup analysis of patients with complicated or refractory disease, CE documented unexpected findings such as strictures, ulcerations and neoplasms in up to $45 \%$ of cases [49]. Of note, CE can only diagnose advanced stages of celiac disease, as early stages are only based on histological findings. The most important use of CE in celiac disease is the evaluation of patients with refractory celiac disease, investigating ulcerative changes or the development of T cell lymphomas. Besides, CE may also be sufficient to diagnose enteropathy-associated $\mathrm{T}$ cell lymphoma which is an intestinal tumor of intraepithelial lymphocytes [50] (fig. 6).

\section{Colon}

\section{Polyps and Cancer}

Colorectal cancer screening still remains a challenge because most patients decline to participate in screening programs due to anxiety directly related to the endoscopic procedure. In this context, the colon capsule has been proposed as an alternative minimally invasive tool for colorectal cancer screening (fig. 7).

In a prospective study, including 84 patients, $\mathrm{CE}$ was followed by standard white-light endoscopy on the same day [51]. $24 \%$ of patients had significant findings, defined as at least one polyp of $6 \mathrm{~mm}$ or more in size or three or more polyps of any size: $70 \%$ were identified with CE and $80 \%$ were identified by conventional colonoscopy. Polyps of any size were found in 45 patients, $76 \%$ found by CE and $80 \%$ by conventional colonoscopy. In comparison with conventional colonoscopy, false-positive findings on CE were recorded in 33\%.

The second-generation colon capsule has several advantages when compared with the first colon capsule. It has an increased angle of view to $172^{\circ}$ and an adaptive frame rate which alternates from 35 frames per second while in motion to 4 images when virtually stationary. This second-generation colon capsule was evaluated by the same group in a prospective, multicenter study [52]. Overall, data from 98 patients were analyzed. The capsule sensitivity for the detection of patients with polyps $\geq 6$ $\mathrm{mm}$ was $89 \%$ (95\% CI 70-97) and for those with polyps $\geq 10 \mathrm{~mm} 88 \%$ (95\% CI 56-98). Specificity of CE for polyps $\geq 6 \mathrm{~mm}$ was $76 \%$ (95\% CI 72-78) and for those with polyps $\geq 10 \mathrm{~mm}$ it was $89 \%$ (95\% CI 86-90), respectively.

In addition, one recent study evaluated the feasibility, accuracy, and safety of the second-generation $\mathrm{CE}$ in a head-to-head comparison with colonoscopy [53]. Data from 109 patients were analyzed. The per-patient CE sensitivity for polyps $\geq 6 \mathrm{~mm}$ and $\geq 10 \mathrm{~mm}$ was 84 and $88 \%$, with specificities of 64 and 95\%, respectively. All 3 invasive carcinomas in the study population were detected by CE.

One large multicenter study included 328 patients and analyzed CE versus conventional colonscopy for the detection of polyps and cancer [54]. The CE was excreted within $10 \mathrm{~h}$ after ingestion and before the end of the lifetime of the battery in about $93 \%$ of patients. CE yielded a 
sensitivity and specificity for detecting polyps $\geq 6 \mathrm{~mm}$ of $64 \%$ (95\% CI 59-72) and 84\% (95\% CI 81-87), respectively. For the detection of advanced adenoma, the sensitivity and specificity were 73\% (95\% CI 61-83) and 79\% (95\% CI 77-81), respectively. Of 19 cancers which were detected by colonoscopy, 14 were also detected by CE (sensitivity 74\%; 95\% CI 52-88). Mild-to-moderate adverse events were reported in about $8 \%$ of patients and were mostly related to the colon preparation.

It is still under debate if patients should undergo sameday colonoscopy in the setting of positive $\mathrm{CE}$ findings. In our opinion, it would be useful that the patient sign the informed consent for colonoscopy together with the informed consent for the capsule. The colonoscopy could then be performed on the same day, given the fact that the patient is good prepared for the colonoscopy, and does not have to undergo another preparation.

\section{Future Concepts of Capsule Endoscopy}

Small bowel imaging still remains the major indication for CE. Comparative studies between the Given Imaging and the Olympus CE have demonstrated similar efficacies of both systems [55]. Currently, new capsule devices are under development in order to enable targeted drug administration or even direct hemostatic therapy. The results of the respective pilot studies are highly anticipated as they will open new applications for CE.

In its current form, the colon capsule is no real alternative to conventional colonoscopy. CE procedure-related costs are extremely high and an exhaustive bowel preparation is needed to obtain reasonable polyp detection rates. Moreover, CE is not sensitive enough to predict histology of colorectal polyps so that every positive CE finding needs to be clarified by conventional endoscopy.

Nevertheless, new capsule devices may improve both, polyp detection and characterization rates. In this context, externally rechargeable batteries (using RF, microwave, ultrasound or electric induction) or even 'battery free' CE are developed. Moreover, integration of virtual chromoendoscopy techniques, like FICE or i-scan, will further improve image resolution and will help to better characterize colorectal lesions [56, 57]. Other devices such as capsules which will enable confocal imaging with near infrared light are also under development thereby allowing obtaining an optical biopsy during the CE procedure. The NEMO (nano-based CE with molecular imaging and optical biopsy) project tends to develop a new capsule that will combine optical and nano technologies, biosensing, and maneuvering technologies in order to further improve diagnostic and therapeutic possibilities of the capsule system [56, 57]. Additionally, pilot studies have already demonstrated the feasibility of new capsule devices to obtain mucosal biopsies and to apply clips or coagulation for hemostasis. In order to actively control the $\mathrm{CE}$, recently the prototype of a magnetically guided capsule endoscope (MGCE) system from Siemens and Olympus was introduced. The study demonstrated that the new technology appears to be feasible and sufficiently accurate for gastric examination and may permit endoscopic examinations that are more patient-friendly and without sedation [58].

\section{Conclusion}

CE has proven its efficacy in multiple trials since its introduction nearly 12 years ago. The main indications for CE interventions are still obscure GI bleeding, followed by clinical symptoms only and suspected Crohn's disease. Multiple studies have shown that CE for these interventions is superior to radiologic interventions and push enteroscopy. In case of positive CE findings balloon-assisted endoscopy (i.e. single- and double-balloon enteroscopy) offers the potential to apply targeted biopsies or therapy.

In the past, CE was only a diagnostic test and capsule movement was passive according to the gut movement. In the future, new capsule devices may offer a great potential for minimally invasive diagnosis and targeted therapy. Moreover, capsule movement will be actively controllable thereby opening new avenues for advanced specific diagnosis and targeted therapy.

\section{Disclosure Statement}

None.

References

1 Iddan G, Meron G, Glukhovsky A, et al: Wireless capsule endoscopy. Nature 2000; 405:417.

$\checkmark 2$ Liao Z, Gao R, Xu C, et al: Indications and detection, completion, and retention rates of small-bowel capsule endoscopy: a systematic review. Gastrointest Endosc 2010;71:280286.

3 Fry LC, Carey EJ, Shiff AD, et al: The yield of capsule endoscopy in patients with abdominal pain or diarrhea. Endoscopy 2006;38: 498-502.

4 Rey JF, Gay G, Kruse A, et al: European Society of Gastrointestinal Endoscopy guideline for video capsule endoscopy. Endoscopy 2004;36:656-658. 
5 Mishkin DS, Chuttani R, Croffie J, et al: ASGE Technology Status Evaluation Report: wireless capsule endoscopy. Gastrointest Endosc 2006;63:539-545.

6 Lewis B: How to prevent endoscopic capsule retention. Endoscopy 2005;37:852-856.

-7 Mönkemüller K, Bellutti M, Fry LC, et al: Enteroscopy. Best Pract Res Clin Gastroenterol 2008;22:789-811.

8 Cuschieri JR, Osman MN, Wong RC, et al: Small bowel capsule endoscopy in patients with cardiac pacemakers and implantable cardioverter defibrillators: outcome analysis using telemetry review. World J Gastrointest Endosc 2012;4:87-93.

-9 Eliakim R, Sharma VK, Yassin K, et al: A prospective study of the diagnostic accuracy of PillCam ESO esophageal capsule endoscopy versus conventional upper endoscopy in patients with chronic gastroesophageal reflux diseases. J Clin Gastroenterol 2005;39: 572-578.

10 Gralnek IM, Adler SN, Yassin K, et al: Detecting esophageal disease with second-generation capsule endoscopy: initial evaluation of the PillCam ESO 2. Endoscopy 2008;40: 275-279.

11 Heresbach D, Leray E, d'Halluin PN, et al: Diagnostic accuracy of esophageal capsule endoscopy versus conventional upper digestive endoscopy for suspected esophageal squamous cell carcinoma. Endoscopy 2010; 42:93-97.

12 Guturu P, Sagi SV, Ahn D, et al: Capsule endoscopy with PILLCAM ESO for detecting esophageal varices: a meta-analysis. Minerva Gastroenterol Dietol 2011;57:1-11.

-13 Pennazio M, Eisen G, Goldfarb N, et al: ICCE consensus for obscure gastrointestinal bleeding. Endoscopy 2005;37:1046-1050.

14 Fry LC, Bellutti M, Neumann H, et al: Incidence of bleeding lesions within reach of conventional upper and lower endoscopes in patients undergoing double-balloon enteroscopy for obscure gastrointestinal bleeding. Aliment Pharmacol Ther 2009;29:342-349.

15 Annibale B, Capurso G, Baccini F, et al: Role of small bowel investigation in iron deficiency anaemia after negative endoscopic/histologic evaluation of the upper and lower gastrointestinal tract. Dig Liver Dis 2003;35: 784-787.

16 Costamagna G, Shah SK, Riccioni ME, et al: A prospective trial comparing small bowel radiographs and video capsule endoscopy for suspected small bowel disease. Gastroenterology 2002;123:999-1005.

-17 Hara AK, Leighton JA, Sharma VK, et al: Small bowel: preliminary comparison of capsule endoscopy with barium study and CT. Radiology 2004;230:260-265.

18 Melmed GY, Lo SK: Capsule endoscopy: practical applications. Clin Gastroenterol Hepatol 2005;3:411-422.
19 Hartmann D, Schmidt H, Bolz G, et al: A prospective two-center study comparing wireless capsule endoscopy with intraoperative enteroscopy in patients with obscure GI bleeding. Gastrointest Endosc 2005;61:826832.

20 Pennazio M, Santucci R, Rondonotti E, et al: Outcome of patients with obscure gastrointestinal bleeding after capsule endoscopy: report of 100 consecutive cases. Gastroenterology 2004;126:643-653.

21 Saurin JC, Delvaux M, Vahedi K, et al: Clinical impact of capsule endoscopy compared to push enteroscopy: 1-year follow-up study. Endoscopy 2005;37:318-323.

22 Delvaux M, Fassler I, Gay G: Clinical usefulness of the endoscopic video capsule as the initial intestinal investigation in patients with obscure digestive bleeding: validation of a diagnostic strategy based on the patient outcome after 12 months. Endoscopy 2004; 36:1067-1073.

23 Matsumoto T, Esaki M, Moriyama T, et al: Comparison of capsule endoscopy and enteroscopy with the double-balloon method in patients with obscure bleeding and polyposis. Endoscopy 2005;37:827-832.

24 Sheibani S, Levesque BG, Friedland S, et al: Long-term impact of capsule endoscopy in patients referred for iron-deficiency anemia. Dig Dis Sci 2010;55:703-708.

25 Bailey AA, Debinski HS, Appleyard MN, et al: Diagnosis and outcome of small bowel tumors found by capsule endoscopy: a threecenter Australian experience. Am J Gastroenterol 2006;101:2237-2243.

26 Cheung DY, Lee IS, Chang DK, et al: Capsule endoscopy in small bowel tumors: a multicenter Korean study. J Gastroenterol Hepatol 2010;25:1079-1086.

27 Mavrogenis G, Coumaros D, Renard C, et al: Jejunal gastrointestinal stromal tumor missed by three capsule endoscopies. Endoscopy 2011;43:735-736.

28 Postgate A, Despott E, Burling D, et al: Significant small-bowel lesions detected by alternative diagnostic modalities after negative capsule endoscopy. Gastrointest Endosc 2008;68:1209-1214.

29 Mata A, Llach J, Castells A, et al: A prospective trial comparing wireless capsule endoscopy and barium contrast series for smallbowel surveillance in hereditary GI polyposis syndromes. Gastrointest Endosc 2005;61: 721-725.

30 Delvaux M, Gay G: International Conference on Capsule and Double-Balloon Endoscopy (ICCD), Paris, 27-28 August 2010. Endoscopy 2011;43:533-539.

31 Caspari R, von Falkenhausen M, Krautmacher C, et al: Comparison of capsule endoscopy and magnetic resonance imaging for the detection of polyps of the small intestine in patients with familial adenomatous polyposis or with Peutz-Jeghers' syndrome. Endoscopy 2004;36:1054-1059.
32 Clarke JO, Giday SA, Magno P, et al: How good is capsule endoscopy for detection of periampullary lesions? Results of a tertiaryreferral center. Gastrointest Endosc 2008;68: 267-272.

33 Iaquinto G, Fornasarig M, Quaia M, et al: Capsule endoscopy is useful and safe for small-bowel surveillance in familial adenomatous polyposis. Gastrointest Endosc 2008;67:61-67.

-34 Günther U, Bojarski C, Buhr HJ, et al: Capsule endoscopy in small-bowel surveillance of patients with hereditary polyposis syndromes. Int J Colorectal Dis 2010;25:1377-1382.

- 35 Schulmann K, Hollerbach S, Kraus K, et al: Feasibility and diagnostic utility of video capsule endoscopy for the detection of small bowel polyps in patients with hereditary polyposis syndromes. Am J Gastroenterol 2005; 100:27-37.

-36 Saurin JC, Pilleul F, Soussan EB, et al: Smallbowel capsule endoscopy diagnoses early and advanced neoplasms in asymptomatic patients with Lynch syndrome. Endoscopy. 2010;42:1057-1062.

37 Koornstra JJ: Small bowel endoscopy in familial adenomatous polyposis and Lynch syndrome. Best Pract Res Clin Gastroenterol 2012;26:359-368.

38 Eliakim R, Suissa A, Yassin K, et al: Wireless capsule video endoscopy compared to barium follow-through and computerised tomography in patients with suspected Crohn's disease - final report. Dig Liver Dis 2004;36: 519-522.

-39 Mow WS, Lo SK, Targan SR, et al: Initial experience with wireless capsule enteroscopy in the diagnosis and management of inflammatory bowel disease. Clin Gastroenterol Hepatol 2004;2:31-40.

40 Fireman Z, Mahajna E, Broide E, et al: Diagnosing small bowel Crohn's disease with wireless capsule endoscopy. Gut 2003;52: 390-392.

41 Dubcenco E, Jeejeebhoy KN, Petroniene R, et al: Capsule endoscopy findings in patients with established and suspected small-bowel Crohn's disease: correlation with radiologic, endoscopic, and histologic findings. Gastrointest Endosc 2005;62:538-544.

42 Goldstein JL, Eisen GM, Lewis B, et al: Video capsule endoscopy to prospectively assess small bowel injury with celecoxib, naproxen plus omeprazole, and placebo. Clin Gastroenterol Hepatol 2005;3:133-141.

43 Dionisio PM, Gurudu SR, Leighton JA, et al: Capsule endoscopy has a significantly higher diagnostic yield in patients with suspected and established small-bowel Crohn's disease: a meta-analysis. Am J Gastroenterol 2010; 105:1240-1248.

44 Leighton JA, Triester SL, Sharma VK: Capsule endoscopy: a meta-analysis for use with obscure gastrointestinal bleeding and Crohn's disease. Gastrointest Endosc Clin N Am 2006;16:229-250. 
45 Solem CA, Loftus EV Jr, Fletcher JG, et al: Small-bowel imaging in Crohn's disease: a prospective, blinded, 4-way comparison trial. Gastrointest Endosc 2008;68:255-266.

46 Cheifetz AS, Kornbluth AA, Legnani P, et al: The risk of retention of the capsule endoscope in patients with known or suspected Crohn's disease. Am J Gastroenterol 2006; 101:2218-2222.

47 Neumann H, Fry LC, Rickes S, et al: A 'double-balloon enteroscopy worth the money': endoscopic removal of a coin lodged in the small bowel. Dig Dis 2008;26:388-389.

-48 Rokkas T, Niv Y: The role of video capsule endoscopy in the diagnosis of celiac disease: a meta-analysis. Eur J Gastroenterol Hepatol 2012;24:303-308.
49 Culliford A, Daly J, Diamond B, et al: The value of wireless capsule endoscopy in patients with complicated celiac disease. Gastrointest Endosc 2005;62:55-61.

50 van de Water JM, Cillessen SA, Visser OJ, et al: Enteropathy associated T-cell lymphoma and its precursor lesions. Best Pract Res Clin Gastroenterol 2010;24:43-56.

51 Eliakim R, Fireman Z, Gralnek IM, et al: Evaluation of the PillCam Colon capsule in the detection of colonic pathology: results of the first multicenter, prospective, comparative study. Endoscopy 2006;38:963-970.

52 Eliakim R, Yassin K, Niv Y, et al: Prospective multicenter performance evaluation of the second-generation colon capsule compared with colonoscopy. Endoscopy 2009;41:10261031.

53 Spada C, Hassan C, Munoz-Navas M, et al: Second-generation colon capsule endoscopy compared with colonoscopy. Gastrointest Endosc 2011;74:581-589.
54 Van Gossum A, Munoz-Navas M, Fernandez-Urien I, et al: Capsule endoscopy versus colonoscopy for the detection of polyps and cancer. N Engl J Med 2009;361:264-270.

55 Cave DR, Fleischer DE, Leighton JA, et al: A multicenter randomized comparison of the endocapsule and the Pillcam SB. Gastrointest Endosc 2008;68:487-494.

56 Eliakim R: Video capsule colonoscopy: where will we be in 2015? Gastroenterology 2010;139:1468-1471.

57 Dominitz JA, Ko CW: Will colon capsule endoscopy replace screening colonoscopy? Gastrointest Endosc 2011;74:590-592.

58 Rey JF, Ogata H, Hosoe N, et al: Feasibility of stomach exploration with a guided capsule endoscope. Endoscopy 2010;42:541-551. 